\title{
Clinical and Laboratory Profile of Patients Admitted with Cleistanthus Collinus Poisoning in a Tertiary Care Hospital
}

\author{
Ramya Das N. K., Mary Grace N. C., Indira M., Jayachandran N. V. \\ Department of General Medicine, Government Medical College, Thrissur, India \\ Email address: \\ ramyadasnk@gmail.com (Ramya Das N. K.)
}

\section{To cite this article:}

Ramya Das N. K., Mary Grace N. C., Indira M., Jayachandran N. V. Clinical and Laboratory Profile of Patients Admitted with Cleistanthus Collinus Poisoning in a Tertiary Care Hospital. American Journal of Internal Medicine. Special Issue: Toxicology.

Vol. 3, No. 6-1, 2015, pp. 14-17. doi: 10.11648/j.ajim.s.2015030601.14

\begin{abstract}
Cleistanthus collinus (Oduku) is a common suicidal poison used in rural southern India. There is paucity of information on human studies about this poisoning at global level. We conducted a cross-sectional observatory study to analyse clinical and laboratory profile of patients admitted with Oduku poisoning in Department of General Medicine, Government medical college, Thrissur over a period of one year from 1st January 2013 to 31 st December 2013. Out of the 143 cases of plant poisoning, study population consisted of 76 (53\%) patients who consumed Oduku. Mean age of the population was 33.5 years (+/-SD 16.10). 43 patients (57.33\%) were asymptomatic; among those with symptoms, 41 patients $(54.67 \%)$. had nausea, 33 patients $(44.00 \%)$ had vomiting, 7 patients $(9.33 \%)$ had abdominal pain, 1 patient $(1.33 \%)$ had palpitation and altered sensorium. Hypokalemia was found in 15 patients (19.74\%) on admission, 7 patients (9.33\%) after 24 hours and 8 patients (10.67\%) after 48 hours. ECG changes observed were ST depression (23.68\%), T inversion (23.68\%) and u waves (17.11\%). Mortality rate of Oduku poisoning found in this study was $2.63 \%(\mathrm{n}=2)$ and expired patients showed persistent hypokalemia despite treatment. Oduku plant constitutes a major agent of DSH among the plant poisons in South India. Gastrointestinal, cardiovascular and neurological symptoms are common with oduku poisoning. Hypokalemia and ECG changes are seen, but mortality rate is low.
\end{abstract}

Keywords: Cleistanthus Collinus, Oduku Poisoning, Deliberate Self Harm, Hypokalemia, U Waves

\section{Introduction}

Deliberate self-poisoning is an important problem in the developing world, where the case fatality rate is far higher than in industrialized countries - $20 \%$ vs. less than $1 \%$ in UK. ${ }^{1}$ One reason for this large difference is the lack of antidotes for many of the poisons used in poor agricultural communities. Poisonous plants are a very important method of toxic exposure. The most frequently consumed lethal plant poisons in middle parts of Kerala are Yellow oleander (Thevetia peruviana), Oduku (Cleistanthus collinus) and Abrus precatorius.

Cleistanthus collinus poisoning is a common suicidal poison used in rural southern India ${ }^{2}$.There is paucity of

\footnotetext{
${ }^{1}$ Eddleston M, Sheriff MHR, Hawton K. Deliberate self-harm in Sri Lanka: an overlooked tragedy in the developing world. Br Med J 1998; 317:133-5.

${ }^{2}$ Shankar, V., Jose, V. M., Bangdiwala, S. I., \& Thomas, K. (2009). Epidemiology of Cleistanthus collinus (oduvan) poisoning: clinical features and risk factors for mortality. International Journal of Injury Control and Safety Promotion, 16, 223-
}

information on human studies about this poisoning at global level ${ }^{3}$.Poisoning usually occurs following intentional ingestion of the leaves with mortality as high as $30 \%$, usually occurs 3-7 days after ingestion ${ }^{4}$

It is known by various names in different parts of India viz., Oduku in Malayalam, Oduvanthalai / Nillipalai in Tamilnadu and Pondicherry, Kadishe in Andhra Pradesh, Karlajuri in West Bengal and Garari in the Hindi speaking belt ${ }^{5}$.

\footnotetext{
230. doi:10.1080/17457300903307094.

${ }^{3}$ Bammigatti, C., Surynarayana, B. S., Harichandra Kumar, K. T., \& Ganesh Kumar, S. (2013). Pattern and outcome of Cleistanthus collinus (Oduvanthalai) poisoning in a tertiary care teaching hospital in South India. Journal of Forensic and Legal Medicine, 20, 959-961. doi:10.1016/j.jflm.2013.08.011

${ }^{4}$ SPE Benjamin, M Edwin Fernando, J Jerene Jayanth, B Preetha ,Cleistanthus CollinusPoisoning.journal of association of physicians India vol 54

${ }^{5}$ Asolkar LV, Kakkar KK, Chakre OJ, eds. Second Supplement to Glossary of
} 
All parts of the plant are toxic ${ }^{6}$. Extract of the various plant parts yielded various compounds of which the glycosides, aryl naphthalene lignan lactones are toxic. ${ }^{7}$ These lignan lactones include cleistanthin $\mathrm{A}$ and $\mathrm{B}$, collinusin and diphyllin, which in the past were known collectively as oduvin $^{8}$.

Patients may be asymptomatic or may present with common gastrointestinal symptoms like nausea, vomiting and abdominal pain; occasionally, diarrhoea, constipation, dysphagia, salivation, abdominal distension and decreased bowel sounds ${ }^{9}, 10$.Cardio-respiratory involvement include chest pain, dyspnoea, tachypnea or bradypnea, tachycardia or bradycardia, hypotension and cyanosis ${ }^{11}$. Neurological abnormalities are mydriasis with visual disturbances, muscle cramps, weakness, altered sensorium, giddiness, headache, altered speech, tremors and ptosis ${ }^{12}$.

Documented laboratory abnormalities include hypokalemia with a normal anion gap metabolic acidosis, leucocytosis, elevated transaminases, elevated creatine phosphokinase, hyponatremia, hyperbilirubinemia and coagulopathy ${ }^{13}$.

Mortality occurs in $40 \%$ of patients with C. collinus poisoning. Death usually occurs within 3-7 days of consumption. Hypokalemia has also been found to have an association with mortality ${ }^{14}$.Associations with mortality include a higher number of leaves $(>60)$, consumption of boiled decoction of leaves, older age, underlying chronic disease, altered sensorium, persistent abdominal pain, giddiness after 24 hours, dyspnea, tachycardia (>120/min) or bradycardia $(<60 / \mathrm{min})$, fever, hypotension, abnormal vision, tachypnea, hours, respiratory arrest, severe acidosis, renal failure and $\mathrm{ARDS}^{15}$.

Indian Medicinal Plants with Active Principles Part-1(A-K) (1965-1981) : New Delhi,National Institute of Science Communication(CSIR), 2000:214.

6 Subrahmanyam DK, Mooney T, Raveendran R, Zachariah B. A clinical and laboratory profile of Cleistanthus collinus poisoning. J Assoc Physicians India. 2003;51:1052-4.

7 Satyanarayana P, Subrahmanyam P, Koteswara RP. Chemical constituents of Cleistanthus collinus roots. Indian J Pharm Sci 1984;46:95-96.

8 Rajagopal Naidu S,Venkat Rao P, Subrahmanyam CA.The microscopy and chemistry of oduvin. J Proc Inst Chem India 1944;16:59-63.

9 Thomas K, Dayal AK, Gijsbers A, Seshadri MS. Oduvanthalai leaf poisoning. J Assoc Physicians India. 1987;35:769-71.

10 Nagaraj S. Cardiac toxicity of Oduvanthalai (Cleistanthus collinus) common leaves poisoning in Tamil Nadu (Report of 25 cases) Antiseptic. 1987;84:33-5

11 Shankar V, Jose VM, Bangdiwala SI, Thomas K. Epidemiology of Cleistanthus collinus (oduvan) poisoning: Clinical features and risk factors for mortality. Int $\mathrm{J}$ Inj Contr Saf Promot. 2009;16:223-30.

12 Nagaraj S. Cardiac toxicity of Oduvanthalai (Cleistanthus collinus) common leaves poisoning in Tamil Nadu (Report of 25 cases) Antiseptic. 1987;84:33-5.

13 Eswarappa S, Chakraborty AR, Palatty BU, Vasnaik M. Cleistanthus collinus poisoning: Case reports and review of literature. J Toxicol Clin Toxicol. 2003;41:369-72.

14 Shankar, V., Jose, V. M., Bangdiwala, S. I., \& Thomas, K. (2009). Epidemiology of Cleistanthus collinus (oduvan) poisoning: clinical features and risk factors for mortality. International Journal of Injury Control and Safety Promotion, 16, 223-230. doi:10.1080/17457300903307094.

15 Nampoothiri K, Chrispal A, Begum A, Jasmine S, Gopinath KG, Zachariah A. A clinical study of renal tubular dysfunction in Cleistanthus collinus (Oduvanthalai) poisoning. Clin Toxicol (Phila) 2010;48:193-7.

\section{Materials and Methods}

We conducted a cross-sectional observatory study to analyse clinical and laboratory profile of patients admitted with Oduku poisoning in Department of General Medicine, Government medical college, Thrissur over a period of one year from 1st January 2013 to 31 st December 2013 .All consecutive patients admitted with Oduku poisoning were included in the study. Patients with documented heart disease, patients with cardiac arrhythmia and those who are on treatment for same and patients with renal failure were excluded.

Statistical analysis was done using EPI INFO version 7 and SPSS version 16. Quantitative variables were reported as means + /_SD and the qualitative variables as percentage. The Chi square test and student's $\mathrm{T}$ test were used in analysis of risk factors.

Informed consent was taken from all the patients or his/her legally valid immediate relative. There were no major ethical issues involved as no invasive procedures were done on the patient as a part of the study alone. This study did not have financial support from any source and the study did not cause any additional financial burden to the patient.

Detailed history including the name of plant consumed, time of consumption, part of plant consumed, amount of plant part, time taken after ingestion of poison to receive medical care were asked. The history of consumption of particular plant was brought forward in all cases by either the patient or the relatives, who either witnessed or noted the circumstantial evidence of poison consumption. The natives of palakkad district, from where the majority of cases presented, were all familiar with particular plant, because of its ubiquitous presence in their neighborhood and the high frequency of consumption of the plant for suicidal intent. Some of the patients were shown the samples of plant leaves and seeds for clarification. Plant parts were also noted in vomitus and the gastric lavage aspirate in most of the cases.

Patients were closely monitored for symptoms including nausea, vomiting, abdominal pain or distension, loose stools, palpitation, dyspnoea, altered sensorium, muscle weakness and decreased urine output.

A complete physical examination including pulse, Blood pressure, Respiratory rate, and relevant system examination were done

Laboratory parameters checked were hemogram, blood sugar, liver function tests, renal function tests, serum electrolytes and ECG were checked at admission, 24 hours and 48 hours after admission. Hypokalemia is defined as S.potassium below $3.6 \mathrm{meq} / \mathrm{l}$ and Hyperkalemia as S.potassium above $5.5 \mathrm{meq} / 1$.

Recording of ECG was done using B.P.L. machine and was analysed for rate, rhythm, PR interval, ST-T changes, U waves and QTc.

All the treatment decisions including potassium replacement were at the discretion of treating unit. Outcome was measured by the number of survivors, symptoms pertaining to each system, metabolic and ECG abnormalities. 


\section{Results}

Out of the 143 cases of plant poisoning, study population consisted of $76(53 \%)$ patients who consumed Oduku. Mean age of the population was 33.5 years (+/-SD 16.10), 52.63\% were between 21 to 39 years.(Table 1 )

Table 1. Age distribution of study population

\begin{tabular}{ll}
\hline Age & No of patients \\
\hline 13 to 20 yrs & 15 \\
21 to 40 yrs & 40 \\
41 to 60 yrs & 13 \\
61yrs\&above & 8 \\
TOTAL & 76 \\
\hline
\end{tabular}

Male to female ratio was 0.85 .75 patients $(98.68 \%)$ consumed leaves; only one patient $(1.32 \%)$ consumed seed. Mean duration to receive medical care after consumption of plant was 3.61 hours $( \pm$ SD 1.76$)$, ranging from 1 hour to 8 hours. 43 patients $(57.33 \%)$ were asymptomatic. Among those with symptoms, the most common presenting symptom was nausea in 41 patients $(54.67 \%) .33$ patients $(44.00 \%)$ had vomiting, 7 patients $(9.33 \%)$ had abdominal pain, 1 patient $(1.33 \%)$ had palpitation and altered sensorium. Only 1 patient had bradycardia at the time of admission, all other patients were having normal pulse rate on admission, after 24 and 48 hours. Rhythm was normal in all patients. 17 patients (22.67\%) had systolic BP less than $90 \mathrm{mmHg}$. Mean value of potassium on admission was 3.84 ( \pm SD 0.72$)$; values ranged from 1.7 to 5.2. After 24 hours mean potassium value was 3.9 meq/l ( \pm SD 0.49); values ranged from 2.5 to $5.1 \mathrm{meq} / 1$. After 48 hours mean potassium value was $3.89 \mathrm{meq} / 1$ ( \pm SD 0.43 ); Minimum value was $2.4 \mathrm{meq} / \mathrm{l}$ and maximum value was $5.1 \mathrm{meq} / \mathrm{l}$ (Table 2).

Table 2. Serum potassium.

\begin{tabular}{llll}
\hline S.Potassium & $\begin{array}{l}\text { No of patients on } \\
\text { admission }\end{array}$ & $\begin{array}{l}\text { No of } \\
\text { patients after } \\
\mathbf{2 4} \text { hours }\end{array}$ & $\begin{array}{l}\text { No of patients } \\
\text { after } \mathbf{4 8} \text { hours }\end{array}$ \\
\hline$<3.5 \mathrm{meq} / 1$ & 15 & 7 & 8 \\
$3.5-5.5 \mathrm{meq} / 1$ & 61 & 68 & 67 \\
$>5.5 \mathrm{meq} / 1$ & 0 & 0 & 0 \\
TOTAL & 76 & 75 & 75 \\
\hline
\end{tabular}

ECG changes observed were ST depression (23.68\%), T inversion $(23.68 \%)$ and $u$ waves $(17.11 \%) .20 \%$ of the patients needed oral or parenteral potassium chloride for correction of hypokalemia. Rest needed only supportive measures.

Mortality rate of Oduku poisoning found in this study was $2.63 \%(n=2)$. There was no statistical correlation of mortality with part of plant consumed, timing of medical care received, dyselectrolemia, or systolic BP on admission. Two patients presented with altered sensorium expired. They had persistent hypokalemia, not responding to treatment and showed ST depression in ECG.

\section{Discussion}

C. collinus poisoning is commonly seen in rural area, preferred by young women as a method of deliberate selfharm. A study on acute poisoning in villagers reported $87.8 \%$ of women consumed plant poisons, $44.5 \%$ of them consumed C. collinus. ${ }^{16}$ This female preponderance with this poisoning is evident in most clinical studies. Easy availability and free access to the plant might be the reasons why women prefer this method of deliberate self-harm.

Our study evaluated the clinical features and laboratory abnormalities seen in patients admitted with plant poisoning, and factors predicting poor prognosis.

Among total 143 patients majority (53\%) consumed oduku. Most of the patients were males (41/76).This male preponderance is in contrast to many of the studies where there is female preponderance ${ }^{17}$. In this study female preponderance was seen in the age group of 13 to 20 years where 12 patients out of 15 were females.

Out of 76 patients, $52.3 \%$ were between the young age group of 21 to 40 years .Mean age of the population was 33.5 years.

75 patients consumed leaves, only one patient consumed seeds. No one consumed it after boiling or more than 60 leaves both of which are associated with poor prognosis ${ }^{17}$.There was no association found between part of plant consumed and mortality.

Mean duration to receive gastric lavage after consumption of the plant was 3.61 hours and there was no correlation found between those patients received stomach wash within one hour and more than one hour. This finding was similar to many studies including study by de Silva et $\mathrm{al}^{8}$.

Most of the patients were asymptomatic (57.33\%).Common presenting symptoms were nausea and vomiting. Two patients had altered sensorium and both of them expired. Previous studies demonstrated a clinical picture with nausea and vomiting. Those studies also demonstrated blurring of vision, neuromuscular weakness, respiratory failure' ${ }^{17}$.None of our patient showed these symptoms. This finding might be due to the relatively lesser amount of poison consumed.

All patients except one had normal pulse rate and rhythm on admission. One patient had bradycardia with regular rhythm.17 patients $(22.67 \%$ ) had systolic BP less than 90 $\mathrm{mmHg}$. Systolic BP and mortality doesn't show any relation on statistical analysis.

Hypokalemia was found in 15 patients (19.74\%) on admission, 7 patients $(9.33 \%)$ after 24 hours and 8 patients (10.67\%) after 48 hours. Patients who died showed persistent hypokalemia despite treatment. Hypokalemia is one of the common manifestations of Oduku poisoning which had previously been described as a poor prognostic sign in

\footnotetext{
${ }^{16}$ Aleem MA, Paramasivam M. Spectrum of acute poisoning in villagers. J Assoc Physicians India. 1993;43:85.

${ }^{17}$ Subrahmanyam DK, Mooney T, Raveendran R, Zachariah B. A clinical and laboratory profile of Cleistanthus collinus poisoning. J Assoc Physicians India. 2003;51:1052-4.
} 
various studies similar to our study.

ECG showed ST depression and T inversion in 18 patients $(23.68 \%)$ and $U$ waves in 13 patients. Most common ECG finding noted was ST-T changes, which was found to be a poor prognostic factor like previous studies.

Mortality rate of Oduku poisoning found in this study was $2.63 \%$. This is lower when compared to a study from Srilanka which showed a mortality of $40 \%{ }^{17}$. This reduced mortality rate found in our study might be due to small amount of poison being consumed and also most of them were healthy adults and consumed the poison following an impulsive thought.

\section{Conclusion}

Oduku plant constitutes a major agent of DSH among the plant poisons in South India. Gastrointestinal, cardiovascular and neurological symptoms are common with oduku poisoning. Hypokalemia and ECG changes are seen, but mortality rate is low.

\section{References}

[1] Eddleston M, Sheriff MHR, Hawton K. Deliberate self-harm in Sri Lanka: an overlooked tragedy in the developing world. Br Med J 1998; 317:133-5

[2] Shankar, V., Jose, V. M., Bangdiwala, S. I., \& Thomas, K. (2009). Epidemiology of Cleistanthus collinus (oduvan) poisoning: clinical features and risk factors for mortality. International Journal of Injury Control and Safety Promotion, $16,223-230$.

[3] Bammigatti, C., Surynarayana, B. S., Harichandra Kumar, K. T., \& Ganesh Kumar, S. (2013). Pattern and outcome of Cleistanthus collinus (Oduvanthalai) poisoning in a tertiary care teaching hospital in South India. Journal of Forensic and Legal Medicine, 20, 959-961.

[4] SPE Benjamin, M Edwin Fernando, J Jerene Jayanth, B Preetha, Cleistanthus Collinus Poisoning.journal of association of physicians India vol 54

[5] Asolkar LV, Kakkar KK, Chakre OJ, eds. Second Supplement to Glossary of Indian Medicinal Plants with Active Principles
Part-1(A-K) (1965-1981) : New Delhi,National Institute of Science Communication(CSIR), 2000:214

[6] Subrahmanyam DK, Mooney T, Raveendran R, Zachariah B. A clinical and laboratory profile of Cleistanthus collinus poisoning. J Assoc Physicians India. 2003;51:1052-4

[7] Satyanarayana P, Subrahmanyam P, Koteswara RP. Chemical constituents of Cleistanthus collinus roots. Indian J Pharm Sci 1984;46:95-96.

[8] Rajagopal Naidu S,Venkat Rao P, Subrahmanyam CA.The microscopy and chemistry of oduvin. J Proc Inst Chem India 1944;16:59-63.

[9] Thomas K, Dayal AK, Gijsbers A, Seshadri MS. Oduvanthalai leaf poisoning. J Assoc Physicians India. 1987;35:769-71

[10] Nagaraj S. Cardiac toxicity of Oduvanthalai (Cleistanthus collinus) common leaves poisoning in Tamil Nadu (Report of 25 cases) Antiseptic. 1987;84:33-5

[11] Shankar V, Jose VM, Bangdiwala SI, Thomas K. Epidemiology of Cleistanthus collinus (oduvan) poisoning: Clinical features and risk factors for mortality. Int J Inj Contr Saf Promot. 2009; 16:223-30

[12] Nagaraj S. Cardiac toxicity of Oduvanthalai (Cleistanthus collinus) common leaves poisoning in Tamil Nadu (Report of 25 cases) Antiseptic. 1987;84:33-5.

[13] Eswarappa S, Chakraborty AR, Palatty BU, Vasnaik M. Cleistanthus collinus poisoning: Case reports and review of literature. J Toxicol Clin Toxicol. 2003;41:369-72

[14] Shankar, V., Jose, V. M., Bangdiwala, S. I., \& Thomas, K. (2009). Epidemiology of Cleistanthus collinus (oduvan) poisoning: clinical features and risk factors for mortality. International Journal of Injury Control and Safety Promotion, $16,223-230$.

[15] Nampoothiri K, Chrispal A, Begum A, Jasmine S, Gopinath $\mathrm{KG}$, Zachariah A. A clinical study of renal tubular dysfunction in Cleistanthus collinus (Oduvanthalai) poisoning. Clin Toxicol (Phila) 2010;48:193-7

[16] Aleem MA, Paramasivam M. Spectrum of acute poisoning in villagers. J Assoc Physicians India. 1993;43:85

[17] Subrahmanyam DK, Mooney T, Raveendran R, Zachariah B. A clinical and laboratory profile of Cleistanthus collinus poisoning. J Assoc Physicians India. 2003;51:1052-4 